\title{
ASSURBANIPAL E SUAS MEMÓRIAS: UMA AUTOBIOGRAFIA NA ANTIGUIDADE?
}

\author{
Katia Maria Paim Pozzer*
}

RESUMO: Neste artigo propomos uma reflexão sobre o conceito de memória, sua interseção com as narrativas oficiais da corte assíria e a relação entre memória e identidade. No mundo antigo oriental o gênero autobiográfico, entendido como uma interpretação retrospectiva da própria vida, não existiu, porém muitos soberanos nos legaram extensos documentos que contém narrativas de cunho biográfico. As inscriçōes reais mesopotâmicas, que tipicamente são de caráter comemorativo de conquistas do rei ou crônicas de campanhas militares, falam da carreira e de cenas da vida e, de algum modo, podem ser entendidas como documentos autobiográficos.

PALAVRAS-CHAVE: Memória; autobiografia; narrativa; identidade.

RÉSUMÉ: Cet article propose une réflexion sur le concept de mémoire, son intersection avec les récits officiels de la cour assyrienne et la relation entre la mémoire et l'identité. Dans le monde oriental ancien, le genre autobiographique, compris comme une interprétation rétrospective de la vie elle-même, n’a pas existé, mais de nombreux souverains nous ont donné de longs documents contenant des récits biographiques. Les inscriptions royales mésopotamiennes, qui sont généralement de nature commémorative du roi ou les chroniques de campagnes militaires, parlent de la carrière et des scènes de vie et, en quelque sorte, peuvent être considérés comme des documents autobiographiques.

MOTS-CLÉS: Mémoire; autobiographie; récit; identité.
* Professora Adjunto do Curso de História da Arte - UFRGS. E-mail: pozzer@terra.com.br 

textos oficiais de rei assírio Assurbanipal, datados de 668 a 627 AEC.

É preciso, contudo, diferenciarmos os conceitos de autobiografia e de memória. A autobiografia procura dar conta de uma vida que atingiu o auge de desenvolvimento ou de realização. Autobiografia no sentido moderno pode servir como veículo de autoexame ou meditação, de autoconhecimento, mas também pode construir ou projetar uma autoimagem de si e esta é também uma forte característica dos textos autobiográficos do antigo Oriente Próximo, sobretudo das inscrições reais. Já as memórias apresentam uma recordação e compreensão dos eventos significativos observados, sendo um gênero de documento muito pouco atestado na Mesopotâmia. (GREENSTEIN: 2006, p. 2421).

No mundo antigo oriental o gênero autobiográfico, entendido como uma interpretação retrospectiva da própria vida, não existiu, porém muitos soberanos nos legaram extensos documentos que contêm narrativas de cunho biográfico. Particularmente no antigo Oriente Próximo podemos falar de textos autobiográficos, sem que contudo tratem da história de vida de seus autores. As inscrições reais mesopotâmicas, que tipicamente são de caráter comemorativo de conquistas do rei ou crônicas de campanhas militares, falam da carreira e de cenas da vida e, de algum modo, podem ser entendidas como documentos autobiográficos. Desconhecemos a autoria da maioria destes textos, mas acredita-se que tenham sido elaborados por escribas altamente qualificados da corte ou secretários particulares dos monarcas.

\section{ConteXto Histórico E gEOGRÁfico dA Assíria}

Na região da Alta Mesopotâmia, entre as margens do rio Eufrates e a leste do rio Tigre é que se desenvolveu a Assíria. Nesta região, praticamente desprovida de cidades, algumas implantações urbanas se constituíram ao longo do 
Tigre e, no II milênio AEC, foram reunidas para formar o estado assírio (Fig. 1) e ficaram conhecidas como o Triângulo Assírio: Nínive, Arbela e Aššur (JOANNĖS: 2000, p. 10).

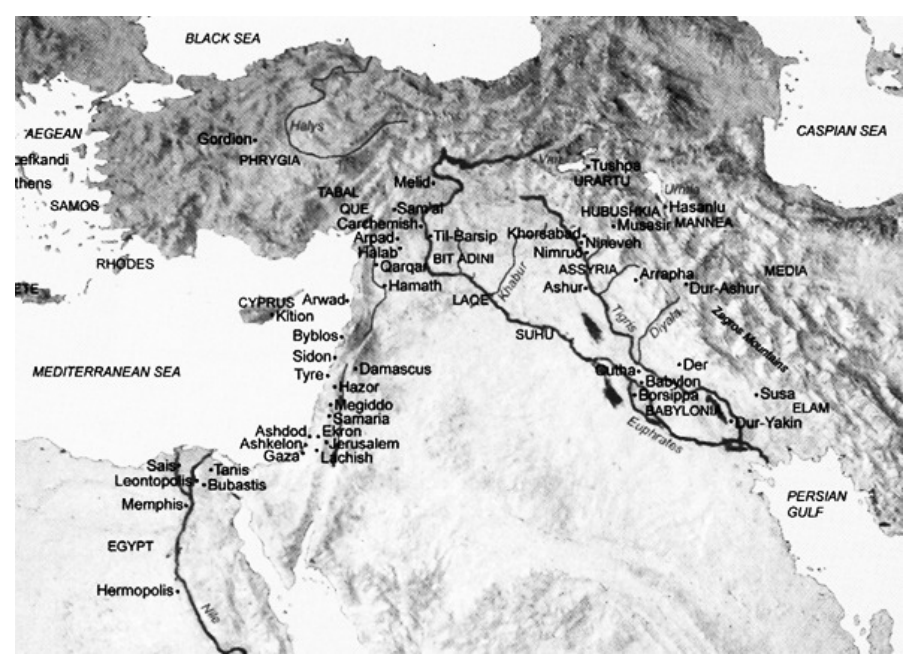

Fig. 1 - Mapa adaptado de COLLINS: 2008, p. 129.

A formação do império assírio foi fruto de um longo processo que visava unir diversos territórios, sob sua língua, sua religião, suas tradiçôes e sua história. Para esse resultado final os soberanos assírios empregaram uma série de guerras, que iniciaram durante o II milênio AEC e se estenderam ao longo do I milênio AEC.

Essas guerras tiveram por vezes um caráter defensivo, por vezes um caráter preventivo e foram destinadas a proteger o território da cidade de Ǎšur, ao longo do rio Tigre, contra seus inimigos e daqueles que tentavam manter fechadas as rotas de comércio indispensáveis a sobrevivência da pequena nação (ROUX: 1995, p. 330).

As primeiras expedições militares fora da Mesopotâmia foram responsabilidade de dois grandes soberanos: TukultiNinurta I (1243-1207 AEC) que venceu a Babilônia e Tiglatpileser I (1112-1074 AEC) que chegou ao Mediterrâneo durante o período médio assírio.

A segunda onda de expansão ocorreu de maneira mais intensa e acelerada. Grandes reis do período neoassírio, com o governo de Adad-Nirari II, iniciando em 912 AEC 
realizaram campanhas militares. De Aššurnasirpal II (883859 AEC) à Aššurbanipal (668-631 AEC), até a queda do império, com a tomada de Nínive, em 612 AEC, a política expansionista vigorou (PARROT: 2007, p. 29-33).

Com a queda do império assírio, em 612 AEC, o legado assírio foi deixado aos impérios posteriores como o neobabilônico, o persa e ao império de Alexandre, o Grande (BEDFORD: 2009, p. 31).

Para a assiriologia (LARSEN: 1979, p. 90) o primeiro império que atingiu extensão de grandes proporções foi o império assírio (Fig. 2), que se dizia herdeiro dos modos de organização imperial e legitimação das épocas de Sargão de Akkad (2340-2159 AEC) e de Hammurabi, rei da Babilônia (1792-1750 AEC), ambos poderosos soberanos do sul mesopotâmico (LIVERANI: 1995, p. 319).

Podemos reconhecer duas grandes fases na formação do império assírio: do século XIII AEC até o ano 1.000 AEC, aproximadamente, e do ano 1.000 AEC até a queda de Nínive em 612 AEC A primeira fase iniciou-se com a emancipação local e regional até as primeiras expedições militares fora do território mesopotâmico, onde se destacam os reis Tukulti-Ninurta I (1243-1207 AEC) que venceu Babilônia e Tiglat-piliser I (1112-1074 AEC). A segunda fase assistiu a extensão da hegemonia política, cada vez mais profunda e longínqua, do império assírio, chegando ao Mediterrâneo. Inúmeros soberanos colecionaram vitórias em campanhas militares, de Assurnazirpal II (883-859 AEC) à Assurbanipal (668-631 AEC), e narraram estes eventos em baixos-relevos em seus palácios. 


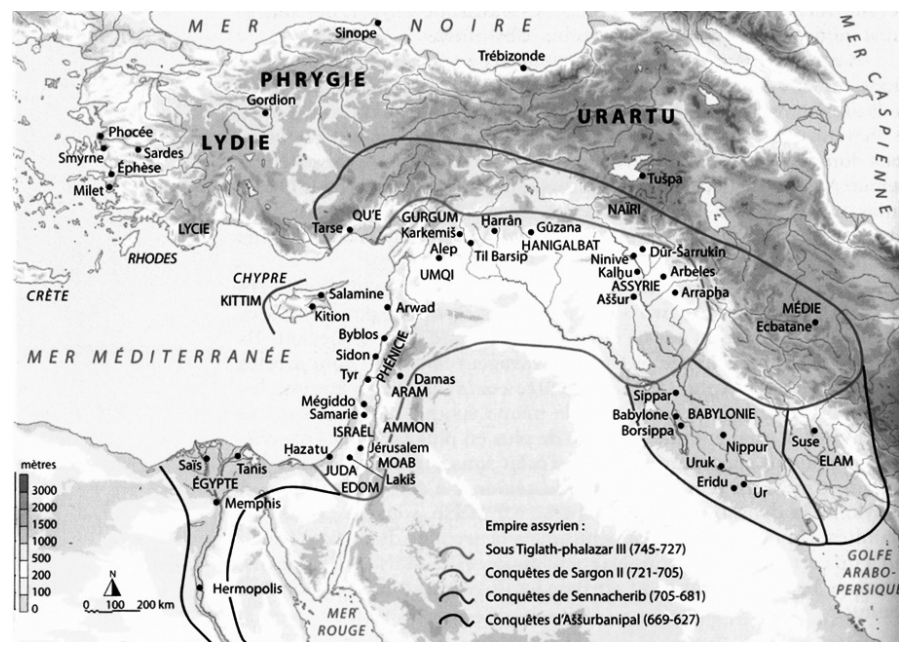

Fig. 2 - Constituição do Império Assírio (adaptado de BORDREUIL; BRIQUEL-CHATONNET; MICHEL: 2008, p. 14)

As escavações arqueológicas que desvendaram os palácios destes soberanos iniciaram no século XIX. O primeiro palácio descoberto foi o de Sargão II, em Dûršarrukin, sobre o sítio de Khorsabad, explorado por Émile Botta em 1843 e 1844, cônsul da França. Após seguiramse as ruínas dos palácios de Kalhu, pelo inglês Henry Austin Layard, desde 1845 , depois Nínive a partir de 1848, por Vitor Place e H. Rawlison. Em 1872, em Nínive, Hormuzd Rassam descobre a Biblioteca de Aššurbanipal e a partir de 1903 até o início da I Guerra Mundial, em Aššur se realizou uma escavação arqueológica que serve de modelo até os dias de hoje (READE: 2006, p. 18).

O sítio arqueológico de Nínive, atualmente no território do Iraque, conheceu várias campanhas de escavaçōes entre os anos de 1852 e 1932. Estas escavaçôes identificaram dois palácios: um localizado a sudoeste, construído por Senaqueribe e conhecido com o "palácio sem rival" e outro, na parte norte do sítio, construído por Assurbanipal (RUSSEL: 1997, p. 295). Na figura abaixo (Fig. 3), identifica-se o palácio norte à esquerda e o palácio sudoeste à direita. 


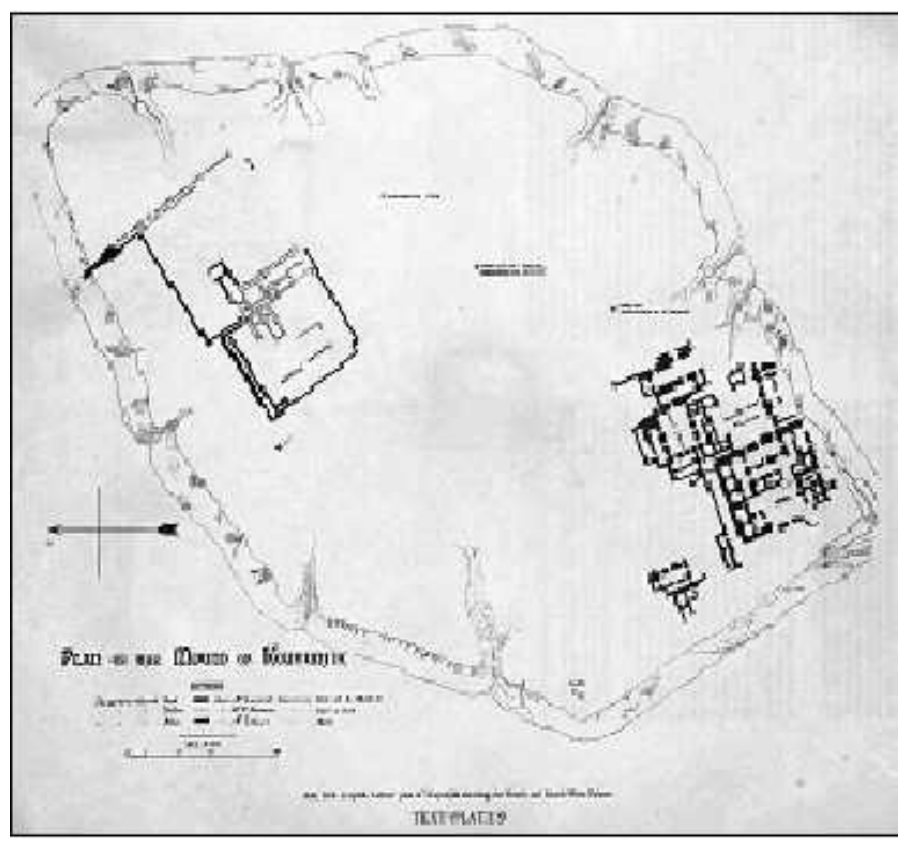

Fig. 3 - Plano de Nínive (BARNETT: 1976, p.24)

Os Anais Assírios do Reinado de Assurbanipal (668-627 AEC)

Os excertos apresentados a seguir são parte integrante de um documento cujo suporte material é um prisma decagonal, proveniente do palácio norte de Nínive, conhecido como Prisma Rassam ou Prisma A. Este magnífico documento, descoberto em 1878, por Hormuzd Rassam, assistente e sucessor das escavações de Henry Layard encontra-se, atualmente, no Museu Britânico (LARSEN: 2001, p. 415).

A tradução exibida a seguir está baseada na obra Annales Assyriennes de Philippe TALON (2011), que realizou uma edição bilíngue, acádico e francês, com textos escolhidos e representativos para cada soberano assírio, onde encontramos a transliteração do texto original em cuneiforme. Para a versão em português me permiti alguma liberdade de adaptação do vocabulário semítico, buscando maior inteligibilidade e compreensão da mensagem, 
fugindo, às vezes, da tradução literal. Trata-se, pois, de documentos inéditos, em língua portuguesa, que oferecemos ao público lusófano, esperando, assim, contribuir para a disseminação dos estudos antigo-orientais.

O primeiro texto encontra-se no início do prisma e é a apresentação do rei Assurbanipal, escrito na primeira pessoa, onde ele elenca suas virtudes e qualidades e, mais importante de tudo, oferece a justificativa ideológica de sua posição, a de que sua escolha como soberano foi obra de seu pai, o rei Assarhaddon e dos deuses do panteão assírio. $\mathrm{O}$ documento diz (I coluna, linhas 1-51):

Eu sou Assurbanipal, (criatura) de Aššur ${ }^{1}$ e de Mullissu, ${ }^{2}$ grande príncipe herdeiro da Casa de Sucessão, dos quais Aššur e Sîn, ${ }^{3}$ senhor (da tiara), pronunciaram, desde muito tempo, o nome da realeza e criaram no seio de sua mãe para o pastoreio da Assíria. Šamaš, ${ }^{4}$ Adad $^{5}$ e Ištar ${ }^{6}$ ordenaram, por uma firme decisão, que eu exerça a realeza. Assarhaddon, rei da Assíria, meu pai, respeitou a palavra de Aššur e de Mullissu, seus aliados divinos, que haviam ordenado que eu exercesse a realeza.

No mês de Ayyarû, ${ }^{7}$ o mês de Éa, ${ }^{8}$ mestre dos povos, no $12^{\circ}$ dia, um dia propício, dia de oferenda alimentar a Gula, ${ }^{9}$ sob ordem sublime que Aššur, Mullissu, Sîn, Šamaš, Adad, Bêl, ${ }^{10} \mathrm{Nabû},{ }^{11}$ Ištar de Nínive, Šarrat-Kidmuri, ${ }^{12}$ Ištar de Arbela, Ninurta, ${ }^{13}$ $\mathrm{Nergal}^{14}$ e Nusku haviam dado, ele agrupou o povo da Assíria, pequenos e grandes, do Mar Superior ao Mar Inferior, e a fim de proteger meu status de príncipe herdeiro e mais tarde o fato que eu exerça a realeza da Assíria, ele os fez pronunciar um juramento de fidelidade em nome dos deuses, reforçando assim o pacto.

Após enunciar uma lista de divindades que protegem seu reinado, Assurbanipal apresenta as habilidades exigidas para um soberano, a saber, o domínio da arte da escrita, do arco e flecha, do cavalo e do carro de guerra. $\mathrm{O}$ documento prossegue:

No gozo e na alegria, eu fiz minha entrada na Casa da Sucessão, lugar perfeito, nó da realeza, onde Senaqueribe, o pai de meu pai, exerceu a função de príncipe herdeiro e de rei, lá onde nasceu Assarhaddon, meu pai e onde ele cresceu e exerceu o poder sobre a Assíria, dirigiu todos os príncipes, ampliou seu clã e solidificou sua casa e sua família.
1. Aššur é o deus do

Estado/nação assírio.

Originalmente era uma divindade local de mesmo nome da cidade e com a transformação da Assíria em um grande império, tornou-se de grande importância em uma enorme extensão territorial (Black; Green: 1998, p. 37-39).

2. Na Assíria Mullissu é a esposa de Aššur, mas na Babilônia Ninlil, como é conhecida, é a esposa do deus Enlil e está associada a maternidade (Black; Green: 1998, p. 140-141).

3. O deus Lua, divindade masculina, é filho de Enlil e Ninil.

4. O deus-sol é a divindade da justiça.

5. Para os sumérios é o deus que personifica o poder da tempestade e tem por nome Iškur. No norte mesopotâmico está associado às chuvas e às cheias dos rios benéficas para as plantaçôes. $\mathrm{Na}$ cidade de Aššur havia dois zigurates, um dedicado a Anu, divindade primordial, e outro a Adad (Black; Green: 1998, p. 110-111).

6. Deusa do amor e da guerra. No período neoassírio era representada por um nu frontal, portando armas e tendo por símbolo uma estrela ou uma roseta (Black; Green: 1998, p. 109).

7. Ver calendário assíriobabilônico e seu correspondente no sistema juliano (Pozzer: 2013, p. 12-23). 
8. Éa, em acádico ou Enki em sumério, é o deus criador da humanidade segundo a mitologia mesopotâmica.

9. A deusa Gula é aquela que "entende de doenças", é a patrona dos médicos. Seu animal sagrado é o cão.

10. Bêl significa "senhor", nome usado tardiamente para nomear Marduk, patrono da cidade de Babilônia. Foi uma divindade popular na Assíria no século XIV AEC (Black; Green: 1998, p. 128).

11. Nabû é a divindade da escrita, o escriba divino dos destinos. Foi uma das principais divindades cultuadas no reinado de Assarhaddon e Assurbanipal (Black; Green: 1998, p. 134).

12. Nome de divindade feminina.

13. Ninurta na Assíria tinha caráter de deus guerreiro e era o esposo da deusa Gula. (Black; Green: 1998, p. 148).

14. Nergal ou o deus Erra, a divindade guerreira por excelência, era o esposo de Ereškigal, rainha do submundo e irmã de Ištar.
Eu também, Assurbanipal, eu aprendi a sabedoria de Nabû, eu examinei os mistérios da arte de escrever de todos os sábios, tantos quanto existem. Eu aprendi a atirar com arco [e flecha], a montar sobre um cavalo ou um carro e segurar as rédeas.

Sob ordem dos grande deuses dos quais eu pronunciei o nome e dos quais eu canto a glória, eles, que ordenaram que eu exercesse a realeza, me confiaram a responsabilidade de manter seus santuários e, em meu lugar, fizeram prestar contas aos meus adversários e mataram meus inimigos.

Eu sou um herói valente, amado de Aššur e de Ištar, descendência da realeza. Desde que Aššur, Sîn, Šamaš, Adad, Nabû, Ištar de Nínive, Šarrat-Kidmuri, Ištar de Arbela, Ninurta, Nergal e Nusku me instalaram com alegria sobre o trono de meu pai, Adad liberou suas chuvas e Éa abriu as suas fontes. O grão cresceu 5 côvados no sulco [da terra], a espiga era longa de $5 / 6$ de côvado A regularidade das colheitas e a abundância do grão eram constantes, as pastagens eram exuberantes, os pomares estavam magníficos de frutos, as tropas [de animais] se reproduziam regularmente. Durante meu reinado, era a abundância, a prosperidade marcava meus anos, a riqueza se acumulava.

O texto finaliza com a repetição da nominata das divindades protetoras de seu reinado, reiterando a garantia da abundância, da riqueza e da prosperidade no reino da Assíria. Trata-se, também de um discurso político do soberano, garantidor do bem-estar da população.

O segundo texto é a narrativa oficial da guerra contra o Elam, império poderoso que ameaçou constantemente a Assíria e a Babilônia ao longos três mil anos de história na antiguidade. Sua localização era no território que posteriormente ficou conhecido como a Pérsia, onde os Montes Zagros eram uma fronteira natural com a planície mesopotâmica (Fig. 2). Este excerto apresenta um importante evento histórico, a Batalha do Rio Ulai, que também foi imortalizada nos baixos-relevos assírios (III coluna, linhas 27-39):

No curso de minha quinta campanha, eu rumei em direção ao Elam. Sob a ordem de Aššur, Mullissu, Sîn, Šamaš, Adad, Bêl, Nabû, Ištar de Nínive, Šarrat-Kidmuri, Ištar de Arbela, Ninurta, Nergal e Nusku, no mês de Ulûlu, obra das deusas, o mês do rei dos deuses, Aššur, o pai dos deuses Nunamnir, como o ataque de uma tempestade furiosa, eu submergi todo o país do Elam, eu 
cortei a cabeça de Te'ummân, seu rei, o rebelde que tinha feito um complô e eu matei seus guerreiros em quantidades incontáveis.

De minhas próprias mãos eu capturei seus combatentes vivos e eu enchi a planície da cidade de Susa de seus cadáveres, como os espinhosos baltu e ǎ̃âgu. ${ }^{15} \mathrm{Eu}$ fiz correr seu sangue no rio Ulai e eu tingi suas águas como a lã vermelha. Humban-nikaš, filho de Urtaki, o rei do Elam que tinha fugido para a Assíria antes de Te'umman e se tornou vassalo, eu o levei junto comigo ao Elam. Eu o instalei sobre o trono de Te'umman. Tammaritu, seu terceiro filho, que havia fugido junto com ele, eu o instalei como rei na cidade de Hidalu.

A data da guerra de Assurbanipal contra o império elamita é incerta, há hipóteses indicando que teria ocorrido entre 663 e 653 AEC. O rei elamita Tepti-HumanInsušnak, conhecido pelos assírios como Teumman, junto com seu filho Tammaritu são capturados e decapitados (COLLINS: 2008, p. 25).

A mutilação dos corpos era uma prática atestada na Mesopotâmia e no Egito antigos, na iconografia e na produção textual. A identidade do inimigo morto e do grupo social ao qual ele pertencia era colocada em evidência (MINUNNO: 2008, p. 249). Após a batalha as cabeças eram mostradas como troféus e eram testemunhas do prestígio e da qualidade do exército vitorioso.

O relevo da Batalha de Til-Tuba ou do Rio Ulai, que mostra os assírios vencendo os elamitas no sul do Irã é, indiscutivelmente, a mais refinada composição em larga escala da arte assíria. A derrota do exército elamita é composta de três painéis, dentro de uma série de dez composições, que narram a história completa da campanha militar (WATANABE: 2008). Temos aqui importante exemplo de uma narrativa literária que complementa uma narrativa visual sobre um mesmo evento histórico (POZZER: 2011).

\section{CONCLUSÃo}

No antigo Oriente Próximo, os textos autobiográficos referiam-se a vida e as conquistas de figuras públicas, sobretudo dos reis, em um mundo onde poucos dominaram
15. Trata-se de plantas espinhosas cuja tradução do acádico para línguas modernas é inexistente. 
muitos e levaram uma vida extraordinária. Muitos dos antigos autores escreveram na primeira pessoa para promoverem a si próprios ou, no caso de escribas autores, buscarem a glorificação de seus senhores.

Esta documentação é um exemplo dos usos e abusos da história na construção de uma memória social. Paul Ricœur (2010, p. 93) discute a tese dos abusos da memória resultantes de «uma manipulação concertada da memória e do esquecimento por detentores do poder» e de como este tema interpela a relação entre memória e identidade, coletiva e pessoal. Para o autor (2010, p. 94) a essência do assunto é a «mobilização da memória a serviço da busca de identidade» e as emanaçōes que dela resultam, a saber o excesso de memória - abuso de memória-, e a insuficiência de memória - abuso do esquecimento. Assim é preciso buscar na fragilidade da identidade a resposta para a fragilidade da memória manipulada. Ricœur enumera três causas principais da fragilidade da identidade e que, de certa forma, explicam o caso assírio. A primeira delas é a relação com o tempo, que necessita do recurso à memória (o que sou hoje, o que fui ontem, o que serei amanhã); a segunda trata do confronto com o outro, entendido como uma ameaça. $\mathrm{O}$ outro é diferente de nós/de mim e pode ser perigoso para nossa/minha identidade; e a terceira causa é a herança da violência fundadora, do nascimento das sociedades humanas através da guerra.

O autor (RICEEUR: 2010, p. 95) afirma que:

O que celebramos com o nome de acontecimentos fundadores, são essencialmente atos violentos legitimados posteriormente por um Estado de direito precário. (...). Assim, os mesmos acontecimentos podem significar a glória para uns e humilhação para outros. (...). É assim que se armazenam, nos arquivos da memória coletiva, feridas reais e simbólicas.

Os textos assírios que apresentamos neste ensaio exemplificam com grande potência este entendimento. Mas, ao mesmo tempo, podemos afirmar que o interesse que os assírios e babilônicos manifestavam pelo seu próprio passado revela uma certa conduta histórica: seu esforço em copiar textos oficiais, em estudar a correspondência real de tempos 
antigos, em constituir séries cronológicas, em esculpir relevos narrando acontecimentos históricos comprovam esta postura.

Alguns destes escribas e reis, historiadores de seu tempo, além de preservarem a memória histórica através de textos e imagens, tentaram explicar os acontecimentos, estabelecendo relações de causa e consequência. Para eles, o passado era fonte de ensinamento histórico, ético e político para os governantes do tempo presente e também instrumento de constituição de uma memória coletiva.

\section{REFERÊNCIAS}

BARNETT, R. D. Sculptures from the north palace of Ashurbanipal at Nineveh (668-627 B.C). London: The British Museum Publications, 1976.

BEDFORD, P.R. Neo-Assyrian Empire. In: MORRIS, I.; SCHEIDEL, W. (eds.). The Dynamics of Ancient Empires. State Power from Assyria to Byzantium. Oxford; New York: Oxford University Press, 2009, p. 30-65.

BIENKOWSKI, P.; MILLARD, A. Dictionary of the Ancient near East. Philadelphia: University of Pensylvania Press, 2000.

BLACK, J.; GREEN, A. Gods, Demons and Symbols of Ancient Mesopotamia. London: The British Museum Press, 1998.

BLACK, J.; GEORGE, A.; POSTGATE, N. A Concise Dictionary of Akkadian. Wiesbaden: Harrassowitz Verlag, 2000.

BORDREUIL, P.; BRIQUEL-CHATONNET, F.; MICHEL, C. Les Débuts de l'Histoire. Paris: Éditions de La Martinière, 2008.

CAD. Chicago Assyrian Dictionary. Chicago: The Oriental Institute of the University of Chicago, 1956-2006.

COLLINS, P. Assyrian Palace Sculptures. London: The British Museum Press, 2008.

CURTIS, J. E.; READE, J.E. Art and Empire: Treasures form Assyria in the British Museum. New York: The Metropolitan Museum of Art, 1995. 
GREENSTEIN, E. Autobiographies in Ancient Western Asia. In: SASSON, J. (ed.). Civilizations of the Ancient Near East. New York: Scribner, 2006, p. 2421-2432.

JOANNÈS, F. La Mésopotamie au 1er millénaire avant J.-C. Paris: Armand Colin, 2000.

Mésopotamienne. Paris: Robert Laffont, 2001.

LABAT, R.; MALBRAN-LABAT, F. Manuel d'Épigraphie Akkadienne. Paris: Geuthner, 1988.

LARSEN, M.T. (ed.) Power and Propaganda: A Symposium on Ancient Empires. Copenhagen: Akademisk Forlag. 1979. La Conquête de l'Assyrie 1840-1860. Paris:

Hachette, 2001.

LAYARD, A.H. The Monuments of Niniveh. London: John Murray, 1853.

LIVERANI, Mario. El Antiguo Oriente. Historia, sociedad y economía. Barcelona: Ed. Crítica, 1995.

MINUNNO, G. La Mutilation du corps de l'ennemi. In: ABRAHAMI, Ph.; BATTINI, L. Les armées du Proche-Orient (III-Ier mill. av. J.-C.). Oxford: British Archaelogical Reports, 2008, p.247-256.

PARROT, A. Assur. Paris: Gallimard, 2007.

POZZER, K.M.P. Uma História Assíria: o espetáculo do terror em uma composição artística. In: ROSA, C.B.; MARQUES, J.B.; TACLA, A.B.; MENDES, N.M. (orgs.). A Busca do Antigo. Rio de Janeiro: Nau Editora, 2011.

Medir o Tempo, um Saber Mesopotâmico. Revista NEARCO. Ano VI, no I, 2013, p. 12-23.

READE, J. Assyrian Sculpture. London: The British Museum Press, 2006.

RICEUR, P. A Memória, a história, o esquecimento. Campinas: Editora da Unicamp, 2010.

ROUX, G. La Mésopotamie. Paris: Éditions du Seuil, 1995. 
RUSSELL, J.M. Sennacherib's Palace Without Rival Revisited: Excavations at Nineveh and the British Museum Archives. In: PARPOLA, S.; WHITING, R. Assyria 1995. Helsinki: University of Helsinki, 1997, p. 295-306.

TALON, Ph. Annales Assyriennes. D’Assurnasirpal II à Assurbanipal. Vol 1. Bruxelles: Éditions Modulaires Européennes, 2011.

WATANABE, C. The Classification of methods of pictorial narrative in Assurbanipal's Reliefs. Studies in Ancient Oriental Civilization. n.62, p. 321-331, 2008. 
Anexo I

Calendário Mesopotâmico

\begin{tabular}{|c|c|c|}
\hline & sumério & acádico \\
\hline I & BARÁ.ZAG.GAR & nisannu \\
\hline II & $\mathrm{GU}_{4}$ SISÁ & ayyaru \\
\hline III & $\mathrm{SIG}_{4} \cdot \mathrm{GA}$ & simânu \\
\hline IV & ŠU.NUMUN & tammuzu \\
\hline $\mathrm{V}$ & NE.IZI.GAR & $a b u$ \\
\hline VI & KIN.INANNA & elûlu \\
\hline VII & $\mathrm{DU}_{6} \cdot \mathrm{KU}$ & tašrîtu \\
\hline VIII & APIN.DU ${ }_{8} \cdot A$ & arahsammu \\
\hline IX & GAN.GAN.E & kislimu \\
\hline $\mathrm{X}$ & AB.BA.È & tebêtu \\
\hline $\mathrm{XI}$ & ZÍZ.ÀM & šabâtu \\
\hline XII & ŠE.KIN.KU & addaru \\
\hline
\end{tabular}

Calendário Mesopotâmico

(adaptado a partir de LABAT: 1988, p. 289).

Enviado em janeiro de 2014

Aprovado em abril de 2014. 